Artigo original

Hegemonia - Revista Eletrônica de Relações Internacionais do Centro Universitário Unieuro

ISSN: $1809-1261$

UNIEURO, Brasília, número 11, 2013, pp. 99-140

Recebido em: $17 / 9 / 2012$

Revisado em: 20/11/2012

Aprovado em: 29/1/2013

\title{
POLÍTICAS PÚBLICAS DE INCLUSÃO NO ENSINO SUPERIOR NO BRASIL: UM ESTUDO DO PROGRAMA UNIVERSIDADE PARA TODOS (ProUni)
}

MINADEO, Roberto ${ }^{1}$

Resumo: A importância e a natureza do ProUni são o foco do artigo. São descritas características e alguns resultados do Programa, dado de que ao início de 2012 o milionésimo aluno foi contemplado com uma bolsa do ProUni. O texto busca inúmeras fontes, e articula ideias com base em dados, evitando os projetos que não vieram a se concretizar como as diversas idas e vindas ocorridas no Congresso, até a aprovação da norma final. Além disso, o ordenamento jurídico foi apresentado da maneira mais concisa possível - apenas para enquadrar o tema - por não ser objeto deste estudo. Análises precipitadas e futurísticas a respeito do programa não tiveram espaço neste artigo, pelo fato de terem sua validade já vencida no todo ou em parte, ou por não apresentarem sólido embasamento. Um enorme esforço se empreendeu no sentido de evitar vieses políticos - mediante leituras das mais diversas correntes de pensamento, e de dar espaço a todas. Apontamse críticas oriundas dessas diversas fontes, havendo uma visão panorâmica - fornecendo uma ampla gama de possibilidades ao leitor de se posicionar em relação ao tema. As conclusões são baseadas no estudo empreendido, e mostram conexão com o progresso do ensino superior do país nas últimas décadas, o ProUni, suas características e principais resultados.

1 Doutor em Engenharia da Produção e servidos do Conselho Nacional de Desenvolvimento Científico e Tecnológico. 
Artigo original

Hegemonia - Revista Eletrônica de Relações Internacionais do Centro Universitário Unieuro

ISSN: $1809-1261$

UNIEURO, Brasília, número 11, 2013, pp. 99-140

Palavras Chave: ProUni; Programa de Bolsas de Estudo Governamentais; Desenvolvimento Educacional e Social; Financiamento Público do Ensino; Cooperação entre ensino público e privado.

Abstract: The importance and nature of ProUni are the focus of the article. There are described some features and results of the program, given that in the beginning of 2012 the millionth student was awarded a scholarship from ProUni. The text seeks to numerous sources, and articulates ideas based on data, avoiding projects that did not come to fruition - as the various comings and goings that took place in Congress, until the approval of the final rule. In addition, the law was presented the most concise way possible - just to frame the issue because law detailed aspects are not the object of this study. Finally, hasty and futuristic about the program did not have space in this article, because they have already won their validity in whole or in part, or for not having solid foundation. A massive effort was undertaken in order to avoid political bias - through readings from various schools of thought, and make room for all. They point to these criticisms coming from various sources, with a panoramic view - providing all the reader a chance to stand on the issue. The conclusions are based and connected in all the study and can show the effort to understand the recent progress in Superior Education in the country, ProUni, its characteristics and main results.

Key-words: ProUni; Program Scholarships Government; Educational and Social Development; Public Education Funding; Cooperation between public and private education.

Introdução - Desigualdades no Brasil e Importância do Ensino Superior

O médico Luiz Couty, pesquisador do Museu Nacional, já advogava em 1879 que além dos Congressos e Revistas focadas na comunidade científica houvesse investimento no país para atingir a parcelas mais 
Artigo original

Hegemonia - Revista Eletrônica de Relações Internacionais do Centro Universitário Unieuro

ISSN: $1809-1261$

UNIEURO, Brasília, número 11, 2013, pp. 99-140

amplas da sociedade no tocante a temas ligados ao desenvolvimento científico e tecnológico (DE REZENDE VERGARA, 2008).

Com a renda dos $20 \%$ mais ricos equivalendo a 33 vezes à renda dos $20 \%$ mais pobres, o Brasil é o país da América Latina mais desigual quanto à distribuição de renda, estando também no grupo dos cinco piores do mundo nesse quesito. Uma das causas foi uma escolha política no início do século no sentido de privilegiar uma nascente classe média urbana. A era Vargas (1930-45) continuou essa tendência: pensões e planos de saúde a trabalhadores ao invés de se contemplar toda a população - tal como se fez no governo Bismarck e suas ferramentas sociais. Apesar da experiência democrática de 1945 a 1964, o sistema social do país permaneceu intocado. A queda dos níveis educacionais dos anos 1960 esteve ligada aos maiores gastos públicos no Ensino Superior nesse período. O sistema de seguros sociais do país retrata o quadro da América Latina do século 20: as aposentadorias privilegiam os trabalhadores do sistema formal, servidores públicos, militares e membros da classe média (HUNTER; SUGIYAMA, 2009).

Na educação, a situação do país era igualmente grave. Segundo um estudo divulgado em fevereiro/2012, da ONG Todos pela Educação, 3,8 milhões de crianças e adolescentes entre 4 e 17 anos estavam fora da escola em 2010. O número de jovens dentro da escola representa $91,5 \%$ da população nesta faixa etária. Além disso, as crianças de seis a 14 anos de idade fora da escola eram 966 mil em 2010 (3,3\% ante $5,5 \%$ em 2000). As regiões Norte e Nordeste reduziram a quantidade de 
Artigo original

Hegemonia - Revista Eletrônica de Relações Internacionais do Centro Universitário Unieuro

ISSN: $1809-1261$

UNIEURO, Brasília, número 11, 2013, pp. 99-140

crianças fora da escola, segundo o IBGE, no período de 2000 a 2010, mas ainda apresentam a maioria no país. Em Santa Catarina foi detectada a menor evasão escolar. Houve queda também na faixa de estudantes de 15 a 17 anos (BORLINA FILHO, 2012; PAÍS..., 2012).

A correção de distorções para o ingresso dos grupos menos favorecidos no ensino superior possui não apenas caráter de justiça social, mas é a solução mais viável para a expansão do nível de ensino. Algumas estratégias no sentido de ações afirmativas são a criação de cotas no vestibular e o ProUni (SOTERO, 2009).

A importância dos estudos universitários se destacam com esses dados da crise deflagrada em 2008 nos EUA: cerca de dois terços dos trabalhadores desse país apenas possui diploma de high school; e mais de $10 \%$ deles perderam seus empregos entre 2007 e 2011, segundo o Urban Institute. Cerca de um terço dessas perdas ocorreu após a recuperação de 2009 em diante. Para os que sequer completaram o high school, o índice de desemprego foi o dobro (FLETCHER, 2012).

Segundo a UNESCO, em 1960 o mundo somava 13 milhões de pessoas estudando em IES. Esse valor subiu a 82 milhões em 1995 e a 132 milhões em 2004. Nos países latino americanos, o número de estudantes nas IES passou de menos de um milhão nos anos 60 para 12 milhões nos anos 1990. O Brasil não estava à margem desse esforço, havendo um conjunto de políticas públicas visando ampliar o número de alunos no ensino superior, seguindo dois critérios: a) existência de 
Artigo original

Hegemonia - Revista Eletrônica de Relações Internacionais do Centro Universitário Unieuro

ISSN: $1809-1261$

UNIEURO, Brasília, número 11, 2013, pp. 99-140

vagas suficientes aos que possuam um mínimo de preparo; e b) chances justas de ingressar nas IES de sua escolha. Muitas iniciativas de ampliação do Ensino Superior apenas atendem ao primeiro princípio. Além disso, no caso da necessidade de seleção, esta não pode estar unicamente centrada em fatores socioeconômicos (MCCOWAN, 2007; ANHAIA, 2010).

A globalização da economia desencadeada pela Revolução da TI, além de fortes mudanças sociais, econômicas e políticas, altera a forma de se conceber a educação: esta passa a formar o trabalhador flexível que a nova situação exige. A IES atual faz frente aos dilemas atuais, apresentando alternativas teórico-práticas para satisfazer às necessidades materiais e simbólicas das pessoas. Cabe, assim, que as IES sejam propulsoras da diversidade ao lado do avanço científico e tecnológico (SOUZA \& OLIVEIRA, 2003; PEREIRA \& SILVA, 2010).

Nos anos 80 e 90 ninguém dos EUA discutiria o valor do ensino superior - apesar de haver quem apontasse que nem Bill Gates nem Steve Jobs atingiram esse nível. O número de críticos cresceu: os custos de uma universidade pública cresceram 3,59 vezes de 1980-81 a 2010-11, segundo o College Board. Os institutos privados apresentaram crescimento comparável de 2,86 vezes. Além disso, há quem diga que as modernas tecnologias da informação estão tornando os universitários um caro anacronismo. Os ambientes de trabalho possuem computadores, software e inteligência artificial - ligados em ambiente global. Assim, passou-se a temer que advogados e médicos poderiam 
Artigo original

Hegemonia - Revista Eletrônica de Relações Internacionais do Centro Universitário Unieuro

ISSN: $1809-1261$

UNIEURO, Brasília, número 11, 2013, pp. 99-140

vir a ter o destino que os bancários enfrentaram a partir dos anos 1980. A Recessão iniciada em 2008 e sua lenta recuperação apontam mais do que nunca na direção oposta: a importância da educação: a exigência de formados passou de $28 \%$ em 1973 para 59\% em 2008. O desemprego dentre os graduados é de $4,3 \%$, de $9,5 \%$ entre os que possuem apenas high school e de $13,9 \%$ dentre os que possuem ainda menos tempo de estudo. Além disso, os universitários recebem maiores honorários. Os empregos para os que possuem apenas high school caíram de 55\% da força de trabalho em 1986 para 48\% em 2006. Assim, Karl Marx talvez estivesse certo ao enfatizar o devastador dinamismo do capitalismo. À medida que a economia continua a crescer e os empregos se destroem e se refazem, a tendência é que aqueles dotados de maior nível de ensino sejam os beneficiados - ainda que não se possa afirmar que a educação seja uma panacéia, como os citados exemplos de Steve Jobs e de Bill Gates apontam (FARRELL, 2011).

Peter Drucker recomenda uma drástica reorientação educacional, passando de uma concentração quase exclusiva no aprendizado prolongado dos jovens para o aprendizado contínuo dos adultos. $\mathrm{Na}$ mesma direção, Handy recomenda que as empresas necessitam se transformar de caso pensado em locais de aprendizagem, nos quais mudança seja uma oportunidade, e as pessoas cresçam à medida que trabalham (HANDY, 1992; BEATTY, 1998).

Desenvolvimento e Importância das Ações Afirmativas 
Artigo original

Hegemonia - Revista Eletrônica de Relações Internacionais do Centro Universitário Unieuro

ISSN: $1809-1261$

UNIEURO, Brasília, número 11, 2013, pp. 99-140

Esse conceito não é uma novidade: há décadas alguns países, como EUA, Índia, África do Sul e Canadá promovem medidas visando promover a mobilidade social de segmentos excluídos pela sociedade. Nos anos 1990, também houve notável avanço jurídico na Europa. No Brasil já existem 43 IES (Instituições de Ensino Superior) públicas que implementaram afirmativas de inclusão social e étnica, mediante diversos modos. Além disso, o ProUni tem representado o acesso das classes menos favorecidas às IES privadas (SANTOS, 2007).

A importância de políticas afirmativas pode ser mostrada por uma simples estatística: nas cinco maiores instituições bancárias do Distrito Federal (DF) o percentual de negros empregados era de cerca de $10 \%$, quando a população negra com o ensino médio completo nessa região era de $43,7 \%$ em 2004. No Bradesco, segundo informações da própria organização, no DF, apenas $15,1 \%$ de seus funcionários são negros e apenas $10,9 \%$ dos quadros de chefia são oriundos dessa etnia (SANTOS, 2007).

Sotero (2009) em seus estudos, verificou a necessidade de as classes inferiores trabalharem e de, ao mesmo tempo, mediante o estudo superior, procurar melhores oportunidades. Verificou que apenas o título superior é insuficiente para a obtenção de bons empregos - até em função das dificuldades de inserção dessas classes nas boas redes sociais. Dessa forma, procuram aprimorar a formação mediante o estudo de línguas, e posteriores cursos de pós-graduação ou a preparação visando concorrer a cargos públicos. 
Artigo original

Hegemonia - Revista Eletrônica de Relações Internacionais do Centro Universitário Unieuro

ISSN: $1809-1261$

UNIEURO, Brasília, número 11, 2013, pp. 99-140

Em maio/2012, o STF (Supremo Tribunal Federal) julgou constitucional - ProUni, que estabelece ações afirmativas em IES privadas. Os ministros entenderam que o programa iguala as chances de pessoas que não teriam condições financeiras de ingressar na universidade. $O$ programa era contestado pelo partido político DEM, pela Confederação Nacional dos Estabelecimentos de Ensino e pela Federação Nacional dos Auditores Fiscais da Previdência Social, que, dentre outras argumentações, afirmavam que o ProUni criou uma discriminação no País, desrespeitando a Constituição; também diziam que houve inconstitucionalidade técnica na legislação, por dar incentivos fiscais às faculdades que decidiam participar do programa (GALLUCCI, 2012; SELIGMAN, 2012).

Panorama do Ensino Superior no Brasil

Para Bobbio, a igualdade de oportunidades é a prática da justiça quando duas pessoas disputam um mesmo objetivo. Para ele, a igualdade de oportunidades pressupõe pessoas dotadas de recursos semelhantes no objeto em disputa. Assim, a igualdade de oportunidades pressupõe que todos os indivíduos de uma determinada sociedade encontram-se nas mesmas condições para competir pelos recursos escassos que esta sociedade produz. A educação, conforme diversas normas da Constituição é uma obrigação do Estado, sendo pressuposto da cidadania, da dignidade da pessoa humana e do Estado Democrático de Direito (TEOTÔNIO \& SILVA, 2006; PEREIRA \& SILVA, 2010). 
Artigo original

Hegemonia - Revista Eletrônica de Relações Internacionais do Centro Universitário Unieuro

ISSN: $1809-1261$

UNIEURO, Brasília, número 11, 2013, pp. 99-140

Nos anos 60, o programa brasileiro de ampliação ao ensino superior, com o apoio da Aliança para o Progresso, tem como pano de fundo o contexto de Guerra Fria. Outra motivação era uma pressão da classe média - aliada do regime militar desde seu início. Porém, em função das restrições orçamentárias, as inversões do MEC foram inferiores ao período anterior, e sua solução para ampliação do número de vagas foi a renúncia fiscal. O Decreto-Lei no 1572/77 revogou a isenção da contribuição previdenciária das IES privadas, porém manteve a renúncia fiscal para as entidades já beneficiadas e até concedeu prazo para regularizar a situação daquelas com o processo de isenção em trâmite. Até 1996, quase todas as IES privadas tiveram imunidade tributária sobre a renda, os serviços e o patrimônio (CARVALHO, 2005).

A Lei n. 5.172/66, que instituiu o Código Tributário Nacional, e a CF/67 fixaram a nãoincidência de impostos sobre a renda, o patrimônio e os serviços de todos os estabelecimentos de ensino. A imunidade refere-se ao Imposto sobre a Propriedade Predial e Territorial Urbana, o Imposto sobre Serviços de Qualquer Natureza (municipais), além do Imposto sobre a Renda e Proventos de Qualquer Natureza e do Imposto sobre a Propriedade Territorial Rural (para imóveis de zonas rurais), ambos da União. As filantrópicas, além da imunidade, gozam da isenção da cota patronal da Previdência Social - que permitiu ampliar a contratação de pessoal - em contrapartida, exige-se a destinação de $20 \%$ da receita bruta em gratuidade. Viabilizaram-se financiamentos bancários, auxílios externos e a captação de recursos de agências de fomento. Houve 
Artigo original

Hegemonia - Revista Eletrônica de Relações Internacionais do Centro Universitário Unieuro

ISSN: $1809-1261$

UNIEURO, Brasília, número 11, 2013, pp. 99-140

alteração legislativa, pelo artigo 20 da LDB/96: as instituições passaram a ser classificadas em privadas lucrativas e sem fins lucrativos (confessionais, comunitárias e filantrópicas). A mudança ampliou a arrecadação da União e dos municípios, e reduziu a rentabilidade das IES privadas (CARVALHO, 2006).

Até meados dos anos 80 , as IES públicas eram praticamente abertas ao uso de todos - independentemente de maiores definições, enquanto que a Associação Nacional das Universidades Particulares unia quase todas as que não fossem controladas pelo poder público (MAIA, 2009).

A Constituição de 1988, em seu art. 208, inciso V, que trata do dever do Estado para com a educação prevê o cumprimento desse dever segundo a capacidade de cada um. Segundo Costa (2010), trata-se de uma restrição elitista.

O artigo 20 da Lei no 9.394/96 de Diretrizes e Bases da Educação Nacional (LDB) diferenciou institucionalmente as IES privadas - que passaram a ser classificadas em privadas lucrativas e sem fins lucrativos (confessionais, comunitárias e filantrópicas). As primeiras deixaram de se beneficiar diretamente de recursos públicos e indiretamente da renúncia fiscal; as demais permaneceram isentas à incidência tributária (CARVALHO, 2005).

Outra mudança: a LDB potencializou o desenvolvimento da economia de mercado na educação, e a regulamentação da educação profissional 
Artigo original

Hegemonia - Revista Eletrônica de Relações Internacionais do Centro Universitário Unieuro

ISSN: $1809-1261$

UNIEURO, Brasília, número 11, 2013, pp. 99-140

como sistema paralelo, pelo Decreto no. 2.208/97, articulando ensino médio e educação profissional, deixando a este último segmento três níveis: básico, técnico e tecnológico - que passa a ter status de educação superior (ratificado pelo Conselho Nacional de Educação, conforme Parecer CNE/CES 436/2001, Parecer CNE/CP 29/2002 e Resolução CNE 03/2002), porém, com carga horária bem inferior que as demais carreiras desse nível (MOURA, 2007). Assim, entre 2000 e 2010, os ingressantes em cursos superiores tecnológicos subiram 547\% no Estado de São Paulo, enquanto caíram $20 \%$ os das graduações tradicionais - incluindo IES públicas e privadas. Em 2000, os cursos tecnológicos representavam 3,6\% dos novos alunos - índice que passou a 23,3\% em 2000. Em todo o país, 8,5\% dos ingressantes em 2005 já eram também representados pelos tecnológicos - índice que subiu a 14,8\% em 2000. Os cursos mais procurados são: a) Gestão de RH; b) Gestão Logística; c) Análise de Sistemas; d) Gestão Financeira; e e) Marketing (MANDELLI, 2012).

Considerando-se exclusivamente as redes públicas estaduais e municipais do país, o Brasil passou de um atendimento municipal do ensino fundamental, em 1996 , de $54,4 \%$ e de um estadual de $45,6 \%$ para, em 2006, os surpreendentes índices de $62,8 \%$ e $37,15 \%$, respectivamente. Estes dados são mais incríveis ainda, quando se observa a situação da região nordeste, pois, de $45,6 \%$ de atendimento estadual no ensino fundamental e $54,4 \%$, nas redes municipais, em 1996, atingiu-se $23,3 \%$ e $76,7 \%$ de atendimento, respectivamente, em 2006. Segundo o IBGE, em 2000, eram 4,4\% da população com a 
Artigo original

Hegemonia - Revista Eletrônica de Relações Internacionais do Centro Universitário Unieuro

ISSN: $1809-1261$

UNIEURO, Brasília, número 11, 2013, pp. 99-140

graduação completa - índice que passou a 7,9\% da população em 2010. As regiões Norte e Nordeste se destacaram (ARELARO, 2007; BORLINA FILHO, 2012).

Em 2011, o número de alunos na educação básica teve queda de 577.270 alunos em relação ao 2010, passando a 50,9 milhões. A queda na rede pública tem sido mais drástica: uma queda de um milhão de alunos ao ano desde 2004. O ensino médio cresceu 43 mil alunos em 2011 em relação a 2010, chegando a 8.357 .675 alunos. A combinação desses dados coloca um potencial risco não apenas ao crescimento ou sequer à sustentabilidade de todas as IES privadas, mas, combinada com a forte expansão das IES públicas, representa um potencial de diminuição do número de IES privadas. Outro dado importente: ao final de 2011, a maior Universidade do País, a USP, somava 5.865 professores, sendo $84,8 \%$ em tempo integral, e outorgou 3.492 títulos de Mestre e 2.338 de Doutor em 2011. Somava 26,5 mil alunos de pósgraduação em seus dez campi, com 308 mestrados e 299 doutorados ( USP MUDA..., 2012; ENSINO MÉDIO..., 2012).

Financiamento público para alunos de IES privadas

O programa denominado FIES iniciou-se em 1999 pela MP n 1827, que foi reeditada 25 vezes, até transformar-se na Lei $\mathrm{n}^{\circ} 10.260$, de 12/07/2001. O FIES substituiu uma política anterior, a Creduc; e emprestava recursos de até $70 \%$ das mensalidades das IES privadas, cobrando baixas taxas de juros. Os pagamentos se iniciavam após a 
Artigo original

Hegemonia - Revista Eletrônica de Relações Internacionais do Centro Universitário Unieuro

ISSN: $1809-1261$

UNIEURO, Brasília, número 11, 2013, pp. 99-140

formatura. 396.647 alunos se beneficiaram do FIES desde seu início, sendo que muitos deles não teriam tido outra chance de obterem seu curso de Graduação. Mas, a partir de setembro/2005, o FIES passou a financiar apenas $50 \%$ das mensalidades - além de passar a abater a cada tres meses $R \$ 50,00$ correspondentes ao saldo devedor. Em 2010, o FIES passa a ter o Fundo Nacional de Desenvolvimento da Educação FNDE - como agente operador; a taxa de juros foi reduzida de $9 \%$ a $3,4 \%$ ao ano. Além disso, o aluno passou a contar com o Fundo Garantidor, que dispensa o fiador. Nesse ano, foram feitos 47 mil contratos, levando o total do FIES a 562 mil contratos. Além disso, os trâmites podem ser pela Internet. De janeiro a abril de 2012 houve mais 140 mil contratos do FIES - que contava com mais de 1.500 IES privadas credenciadas. (ALMEIDA, 2006; MCCOWAN, 2007; ANHAIA, 2010; COSTA, 2010; MAIS DE..., 2012).

Há uma anomalia clássica no Ensino Superior no Brasil: enquanto no Ensino Médio e Básico as Instituições de maior prestígio são as particulares dado que as públicas não receberam investimentos significativos, no Ensino Superior essa situação se inverte. O país investe no Ensino Superior quase tanto quanto os mais desenvolvidos do mundo, e cerca de sete vezes mais que investe nos níveis básico e médio. Em função disso os alunos provenientes dos colégios particulares apresentarem superiores possibilidades de acesso às IES públicas, com a consequente injustiça, de serem as classes mais abonadas a receberem o ensino público mais caro e de maior qualidade. Destaca-se que a partir dos anos 80 , os investimentos governamentais no ensino 
Artigo original

Hegemonia - Revista Eletrônica de Relações Internacionais do Centro Universitário Unieuro

ISSN: $1809-1261$

UNIEURO, Brasília, número 11, 2013, pp. 99-140

passaram a sofrer maiores aportes - embora com notório viés político. Durante o governo FHC houve a criação do FUNDEF, Fundo de Manutenção e Desenvolvimento do Ensino Fundamental, importante ferramenta para proporcionar recursos e apoio técnico aos Estados e Municípios mais pobres - programa com relativa consolidação no ano 2000. Mas, houve queda na qualidade das IES públicas no governo FHC, por falta de investimentos público e ampliação da atuação privada no ensino superior. O ensino privado sempre contou com inúmeras IES, sendo as confessionais detentoras de características semelhantes às públicas; porém, surgiram IES com perfil mais voltado ao mundo dos negócios, apenas focadas no ensino - criando dois mundos distintos dentre as IES privadas - havendo algumas destas cuja qualidade deixou a desejar (MCCOWAN, 2007; HUNTER \& SUGIYAMA, 2009; COSTA, 2010; MCCOWAN, 2007).

Outro dado interessante: os cursos nas grandes áreas de ciências humanas e de linguística, letras e artes se multiplicaram nos últimos anos com interiorização e expansão nas regiões Norte e Nordeste. Há cursos de letras e linguística em todos os Estados brasileiros, exceto Maranhão. De 2004 a 2009, o número de programas na área passou de 168 para 225. A linguística passou a focar a questão social, não mais sendo vista como apenas teórica e divorciada das questões sociais. Além disso, na área de ciências humanas, o número de programas passou de 421 para 588 entre 2004 e 2009, com forte crescimento no Norte e Nordeste. Na busca da ampliação de cursos com nível de excelência, 
Artigo original

Hegemonia - Revista Eletrônica de Relações Internacionais do Centro Universitário Unieuro

ISSN: $1809-1261$

UNIEURO, Brasília, número 11, 2013, pp. 99-140

têm sido criados programas voltados a demandas regionais vinculadas a políticas públicas (KALENA, 2012).

Quatorze novas IES federais foram criadas de 2003 a 2010 (PEREIRA; SILVA, 2010). Porém, segundo o censo nacional de 2000, a educação superior ainda era uma realidade restrita à elite: dos 170 milhões de habitantes (86 milhões feminina e 84 milhões masculina), apenas 5.890 .631 (2.689.726 homens e 3.200.905 mulheres) tinham acesso ao ensino superior; desses, apenas 5.485 .710 tinham completado a graduação e 302.043 tinham Mestrado/Doutorado (APRILE; BARONE, 2006). De acordo com dados do INEP/MEC, em 2003, apenas $9 \%$ da população de 18 a 24 anos freqüentava o ensino superior (CARVALHO, 2005).

Um dado interessante aponta o esforço governamental para o aprimoramento da educação na última década: o crescimento dos investimentos em Educação e em C\&T no País. Com valores constantes de dezembro/2010 (segundo O IPCA), o governo ampliou os investimentos em Educação de R\$20.829,2 milhões em 2000 para $R$ \$ 49.766,7 milhões - aumento de 139\%. Da mesma forma, as inversões em C\&T cresceram no período de $\mathrm{R} \$ 2.418,5$ milhões para $\mathrm{R} \$ 7.726,2$ milhões - com 219\% de ampliação (FEGHALI \& BAHIA, 2011).

Natureza e Constituição do ProUni 
Artigo original

Hegemonia - Revista Eletrônica de Relações Internacionais do Centro Universitário Unieuro

ISSN: $1809-1261$

UNIEURO, Brasília, número 11, 2013, pp. 99-140

O ProUni é uma política de acesso à Universidade mediante mecanismos de isenção fiscal às IES privadas e filantrópicas, terdo por critério o perfil socioeconômico do potencial beneficiário. Representa uma flexibilização das formas de ingresso nas IES mediante políticas públicas que buscam assegurar o direito de grupos historicamente menos favorecidos - cuja inserção neste nível de ensino confere novas características. O ProUni se sustenta em seis pilares: a) visão sistêmica da educação; b) territorialidade; c) desenvolvimento; d) regime de colaboração; e) responsabilização; e f) mobilização social (ANHAIA \& NEVES, 2009; ANHAIA, 2010; COSTA, 2010).

Devido à resistência organizada de grupos de alunos e professores, com apoio da mídia, o Ensino Superior não sofreu sequer no Governo Lula alterações no sentido de cobrança de mensalidades de alunos afluentes nas IES públicas ou de permitir que nelas ingressassem alunos das classes inferiores. Assim, o ProUni - objeto de estudo deste artigo pode ser encarado como uma solução de compromisso. Assim, vinte anos após a nova Constituição, o país permanece altamente segmentado: os três níveis de educação pública tendem a ser ocupados por pessoas de diferentes classes sociais - sendo as IES públicas ocupadas por membros das classes superiores. Em outras palavras, uma das formas de corrigir as desigualdades é investir socialmente de modo desigual para agir afirmativamente. A educação pode assegurar a liberdade de escolha consciente. O Estado, mediante a educação, deve discriminar positivamente os grupos sociais marginalizados, de forma a propiciar condições de efetiva igualdade substancial com os demais 
Artigo original

Hegemonia - Revista Eletrônica de Relações Internacionais do Centro Universitário Unieuro

ISSN: $1809-1261$

UNIEURO, Brasília, número 11, 2013, pp. 99-140

grupos sociais, permitindo a tão almejada integração (TEOTÔNIO \& SILVA, 2006; HUNTER \& SUGIYAMA, 2009).

O sistema Nacional de Avaliação da Educação Superior - SINAES - foi proposto ao MEC por uma comissão em 2003 e constituída mediante a Lei $\mathrm{n}^{\circ} 10.861$, de 14/04/2004, com o objetivo de conduzir o processo de avaliação da educação superior. Está assentado no tripé: avaliação das instituições de ensino superior; dos cursos de graduação e do desempenho dos estudantes. Foi uma primeira iniciativa de mudança do governo Lula na educação superior. Além disso, foi criado o Fundeb Fundo de Manutenção e Desenvolvimento da Educação Básica mediante a Lei n 11.494 de junho/2007 (OTRANTO, 2006; COSTA, 2010).

O Banco Mundial vê a educação superior no Brasil um campo privilegiado devido aos subsídios governamentais, e propõe que as IES públicas diversifiquem suas fontes de financiamento, como por exemplo, a participação dos estudantes nos gastos e a vinculação entre o financiamento fiscal e os resultados (OTRANTO, 2006).

O ProUni foi criado pela Medida Provisória n. 213, de 10/09/2004, e transformado na Lei n. 11.096, de 13/01/2005. Segundo o MEC, quando o ProUni foi lançado, em 2005, o valor médio por estudante, em renúncia fiscal, foi de $\mathrm{R} \$ 940,54$. O custo médio anual do estudante do ProUni teria caído mais da metade em dois anos, conforme declarações das autoridades do governo. Para 2007, a estimativa divulgada era a de 
Artigo original

Hegemonia - Revista Eletrônica de Relações Internacionais do Centro Universitário Unieuro

ISSN: $1809-1261$

UNIEURO, Brasília, número 11, 2013, pp. 99-140

um custo médio por aluno igual a $R \$ 418,32$. O ProUni quando apenas $13 \%$ dos jovens de 18 a 24 anos estavam matriculados em IES, segundo a Pesquisa Anual por Amostra de Domicílios, PNAD (2003); era um dos mais baixos índices, em relação com: a Argentina (cerca de $40 \%$ ), Venezuela (26\%) e Chile (20,6\%). (APRILE \& BARONE, 2006; SEGENREICH, 2009; ANDRÉS RIBEIRO, 2011).

O ProUni busca promover o acesso à educação superior com baixo custo ao governo, tentando gerir impacto popular, atendimento às demandas do setor privado e de sua ociosidade, e regular as contas do Estado. Além disso, visava cumprir a meta do Plano Nacional de Educação (PNE - Lei no 10.172/2001) de aumentar a proporção de jovens de 18 a 24 anos matriculados em curso superior para 30\% até 2010 (CATANI; HEY; GILIOLI, 2006).

Em setembro/2004 o MEC publicou informações sobre os mecanismos de isenção do ProUni, às IES participantes (PARAGUASSÚ, 2009; ANDRÉS RIBEIRO, 2011):

A) Entidades filantrópicas: imunidade tributária garantida, com pagamento apenas de Cofins e PIS de serviços terceirizados. Devem participar do ProUni para manter a filantropia, investindo $20 \%$ da receita bruta em bolsas de estudo e assistência social, sendo necessariamente $10 \%$ dessa receita na oferta de bolsas de estudo integrais.

B) Entidades sem fins lucrativos: imunidade do Imposto de Renda e isenção da CSLL; recolhimento da cota patronal sobre a folha de 
Artigo original

Hegemonia - Revista Eletrônica de Relações Internacionais do Centro Universitário Unieuro

ISSN: $1809-1261$

UNIEURO, Brasília, número 11, 2013, pp. 99-140

salários, Cofins e PIS. Se aderem, pagam a cota patronal, mas ganham isenção de Cofins, PIS, IR e CSLL. Devem oferecer $10 \%$ das vagas de acesso a bolsas de estudo, sendo $5 \%$ necessariamente bolsas integrais e os outros $5 \%$ poderão ser de bolsas parciais, desde que atenda ao dobro de alunos.

Segundo o MEC, $85 \%$ das IES privadas já usufrui isenção total de tributos, caso das filantrópicas, ou parciais, caso das que não possuem fins lucrativos. Apenas $15 \%$ das IES com fins lucrativos pagam impostos, e podem ter isenção ao aderir ao ProUni; no caso das demais, a isenção já existe, ou seja, basta aderir e ofertar bolsas (COSTA, 2010).

As IES privadas orientadas para a obtenção de lucros são radicalmente diversas das demais: buscam locais onde haja renda suficiente e número de egressos que possam pagar pelos cursos que estejam demandando. Por outro lado, a concorrência acirrada entre grupos com centenas de milhares de alunos leva à severa contenção de despesas o inclui cortes nos honorários dos professores, em função da maior oferta de Mestres e Doutores (ALMEIDA, 2006).

Um estudo interessante é trazido por Ceribeli, Prado e Merlo (2010), que relatam o problema de uma instituição de ensino básico, fundamental e médio que era líder em seu município, mas que passou a sofrer forte queda de alunos após o ingresso de uma concorrente que praticava preços quase $50 \%$ inferiores. Os autores, no Quadro 3, 
Artigo original

Hegemonia - Revista Eletrônica de Relações Internacionais do Centro Universitário Unieuro

ISSN: $1809-1261$

UNIEURO, Brasília, número 11, 2013, pp. 99-140

afirmam como ponto fraco dessa instituição líder a sua coordenação acadêmica muito rígida e inflexível. Apontam como possível oportunidade o ingresso no ensino superior. Essa análise não trata da eventualidade de estudos visando a redução de custos da Instituição analisada.

A Universidade Estácio de Sá, maior IES privada do país à época, com mais de 100 mil alunos, passou de filantrópica para com fins lucrativos. Com a mudança passaris a pagar o valor integral da cota patronal do INSS a partir de 2010; vantagem: não precisar oferecer $20 \%$ de gratuidade, apenas $10 \%$ ( $5 \%$ em bolsas integrais) (CATANI \& HEY \& GILIOLI, 2006).

O Censo da Educação Superior do INEP de 2005 aponta que entre 1992 e 2002 o número de IES públicas caiu de 227 para 195 unidades destacando-se a queda dentre as IES estaduais e municipais. No período, o número de IES particulares subiu de 666 para 1.442 unidades. Além disso, entre 1997 e 2002, o número de vagas ofertadas pelas IES privadas quase triplicou, de 500 mil para 1,5 milhão. O Censo apontou 2.165 instituições de ensino superior (IES) no Brasil, que ofertavam 20,4 mil cursos superiores, com cerca de 4,5 milhões de matrículas. $89,3 \%$ das IES eram privadas - 1.934 ao todo, sendo 1.520 com fins lucrativos - e reuniam 14,2 mil cursos e 3,3 milhões de matrículas (73\% do total). As 231 IES públicas detinham 1,2 milhão de matrículas, em 97 instituições federais, que se destacavam com 579.587 matrículas, 75 estaduais (com 477.349 registros) e 59 
Artigo original

Hegemonia - Revista Eletrônica de Relações Internacionais do Centro Universitário Unieuro

ISSN: $1809-1261$

UNIEURO, Brasília, número 11, 2013, pp. 99-140

municipais (com 135.253 alunos) (ALMEIDA, 2006; ANDRÉS RIBEIRO, 2011).

O ProUni visa estudantes com de até 3 salários mínimos e oriundos de escolas públicas ou privadas na condição de bolsistas - com a nota do Exame Nacional do Ensino Médio (Enem). Parte das bolsas deve ser direcionada a ações afirmativas aos portadores de deficiência, negros e indígenas. A formação de professores de ensino básico da rede pública também é prioritária. Um dos critérios para a permanência do bolsista ProUni no Programa é um rendimento acadêmico em $75 \%$ das disciplinas cursadas, em cada semestre. No caso de não cumprimento desta meta, a Comissão Permanente de Seleção e Acompanhamento poderá autorizar em decisão unânime a manutenção da bolsa, em casos excepcionais e devidamente justificados - observando-se sempre o prazo máximo para a conclusão do curso (CARVALHO, 2006; PARAGUASSÚ, 2009; COSTA, 2010; ANDRÉS RIBEIRO, 2011).

A existência de crescentes vagas ociosas no segmento privado, somado à procura por ensino superior das camadas de baixa renda, provenientes da busca pela universalização do Ensino Médio, fundamentou a proposta do MEC de criação do Programa Universidade para Todos. Diversos estudos vêm demonstrando que, apesar da brutal desigualdade de acesso ao ensino superior entre ricos e pobres, há maior participação das camadas mais pobres nas instituições públicas que nas particulares, materializada na menor participação dos $10 \%$ mais ricos, na maior 
Artigo original

Hegemonia - Revista Eletrônica de Relações Internacionais do Centro Universitário Unieuro

ISSN: $1809-1261$

UNIEURO, Brasília, número 11, 2013, pp. 99-140

parcela dos $50 \%$ mais pobres, na maior proporção de estudantes negros ou pardos e na menor renda média mensal familiar (CARVALHO, 2006).

Levantamento do Cadastro Nacional de Docentes da Educação Superior do INEP, mostrava que dos 252.712 professores atuantes no ensino superior no Brasil no segundo semestre de 2005, 36\% eram mestres; $29 \%$ eram especialistas; $24 \%$ eram doutores; e $11 \%$ eram graduados. Havia ainda 40 professores sem qualquer formação acadêmica (ANDRÉS RIBEIRO, 2011).

\section{ALGUNS RESULTADOS DO PROUNI ATÉ O MOMENTO}

Na PUC-Minas, em 2005, apenas $65,7 \%$ dos candidatos préselecionados ao ProUni foram aprovados pela IES; $21,6 \%$ não compareceram na seleção interna e $12,8 \%$ foram reprovados. Dos aprovados, $17,8 \%$ não se matricularam - motivos: percentual da bolsa parcial insuficiente; aprovação em instituição pública; desinteresse pelo curso selecionado (podem-se escolher até cinco cursos) -, reduzindo a quantidade de bolsistas (CATANI \& HEY \& GILIOLI \& 2006).

Em 2005, primeiro ano de funcionamento do ProUni, a adesão contou com 1.142 das IES privadas do País (60\% do total). Em 2006, foram 1.232 e em 2007, foram 1.424. Até dezembro de 2007, o Programa já contava com a adesão de 1.416 IES na oferta para o primeiro semestre de 2008 (ANDRÉS RIBEIRO, 2011). 
Artigo original

Hegemonia - Revista Eletrônica de Relações Internacionais do Centro Universitário Unieuro

ISSN: $1809-1261$

UNIEURO, Brasília, número 11, 2013, pp. 99-140

No segundo semestre de 2006, houve 200.792 inscrições e apenas $23 \%$ de bolsas concedidas, ou seja, 47.059. Em 2005, 1.142 estabelecimentos particulares aderiram ao programa; em 2006, foram 1.232. A cada semestre são oferecidas de $100 \mathrm{mil}$ a $150 \mathrm{mil}$ bolsas integrais e parciais. Ao início de 2009, o programa atendia cerca de 450 mil alunos (CARVALHO, 2006; PARAGUASSÚ, 2009).

Conforme o MEC, até o final do $1^{\circ}$ semestre de 2006, a análise das três etapas de inscrição do ProUni mostrou que a média de nota do Enem dos estudantes inscritos no ProUni foi $13 \%$ superior à média nacional dos alunos matriculados nas escolas particulares. A pesquisa 'Acesso e permanência - a experiência do ProUni na PUC-Minas', do $1^{0}$ semestre/2005, mostrou que $77,1 \%$ dos alunos que ingressaram pelo ProUni foram aprovados em todas as disciplinas. No mesmo período, a reprovação global por desempenho na universidade foi de $29,7 \%$ contra $22,9 \%$ para os beneficiados pelo Prouni; estes também têm são mais frequentes que os demais: apenas $2,9 \%$ dos bolsistas foram reprovados por freqüência, índice que foi de 9,39\% para o total da universidade. Até o segundo semestre de 2007, cerca de 310 mil alunos haviam sido beneficiadas pelo Programa, em todos os Estados - sendo 73,16\% equivalentes a bolsas integrais (CARVALHO, 2006; PARAGUASSÚ, 2009; ANDRÉS RIBEIRO, 2011).

Cabe apontar que o ENEM, criado em 1998, avalia as competências e habilidades adquiridas nos onze anos de educação básica. Busca avaliar cinco eixos: a) domínio de linguagens; b) compreensão e interpretação 
Artigo original

Hegemonia - Revista Eletrônica de Relações Internacionais do Centro Universitário Unieuro

ISSN: $1809-1261$

UNIEURO, Brasília, número 11, 2013, pp. 99-140

de fenômenos; c) resolução de problemas; d) argumentação; e e) elaboração de propostas (ANHAIA, 2010).

O número de alunos beneficiados pelo programa Bolsa Filantropia da Universidade Católica de Goiás era de 2.934. Destes, apenas 13,94\% seriam atendidos pelos critérios do ProUni. Assim, a implantação desse programa governamental levou a UCG a rever seus critérios de inclusão social - fechando o seu programa Bolsa Filantropia (MAIA, 2009).

A PUC-RJ tinha 11 mil alunos na graduação e concedia 4.300 bolsas, entre parciais e integrais. Segundo a Universidade, isso corresponderia a 3.069 bolsas integrais. O que significa, neste caso, que 1.231 alunos deixariam de ter algum tipo de desconto. Mas o reitor destacou como problema adicional a escolha dos Bolsistas por parte do MEC, desconsiderando, portanto, o vestibular e a autonomia universitária (TEOTÔNIO \& SILVA, 2006).

No segundo semestre de 2007, a PUC-SP somava 15.776 alunos de graduação - dos quais 815 eram bolsistas do ProUni, e 5.019 possuíam algum outro tipo de Bolsas. Desses $815,77,22 \%$ estavam na faixa dos 18 aos 24 anos. Desses 815 Bolsistas, 56,1\% residem na capital paulista e os demais em municípios próximos - o que parece mostrar que o ProUni abrange realmente um público de faixa econômica que dificilmente estaria nessa IES. O maior número de bolsistas estava nos cursos de: Administração (178), Direito (129), Economia (72), Psicologia (41), Letras (30), Contabilidade (30), Relações Internacionais 
Artigo original

Hegemonia - Revista Eletrônica de Relações Internacionais do Centro Universitário Unieuro

ISSN: $1809-1261$

UNIEURO, Brasília, número 11, 2013, pp. 99-140

(29), Medicina (27), Ciências Sociais (26), Jornalismo (25) Pedagogia (25) e História (25). No Censo Educacional de 2006, Administração e Direito são os mais numerosos: do total de 2.629 .598 vagas, Administração ofereceu $520.796(19,8 \%)$ e Direito ofereceu 227.831 $(8,6 \%)($ COSTA, 2010).

Os primeiros recém-formados do ProUni saíram empregados, dizendo que tanto a renda familiar como sua vida melhoraram após o curso segundo pesquisa junto a 1,2 mil pessoas - do total de $156 \mathrm{mil}$ formandos. O levantamento, feito por telefone em março de 2009 pelo Ibope, encomendado pelo MEC, mostrou que $80 \%$ disseram sair da universidade com emprego garantido. Esse índice era de $56 \%$ antes de entrarem no programa; $68 \%$ afirmaram que a renda familiar aumentou desde a entrada na faculdade: $40 \%$ disseram que a melhoria foi pequena; os outros $28 \%$ disseram que foi elevada (PARAGUASSÚ, 2009).

O número de matrículas nas IES brasileiras suciu de 1.759 .703 em 1995 para 4.453.156 em 2005 - crescimento de 153\%. Nesse último ano, o setor privado respondeu por $73,2 \%$ das matrículas. Além disso, das matrículas nas IES privadas em 2005, apenas $8,1 \%$ correspondiam a Universidades - que apresentam deveres de pesquisa, ensino e extensão - sendo as restantes vagas ocupadas por faculdades e centros universitários. A Taxa de Escolarização Bruta da Educação Superior, dentre os jovens de 18 a 24 anos, passou de $1 \%$ para $15 \%$ entre 1962 e 2002, segundo o INEP, porém, ainda representando valores inferiores 
Artigo original

Hegemonia - Revista Eletrônica de Relações Internacionais do Centro Universitário Unieuro

ISSN: $1809-1261$

UNIEURO, Brasília, número 11, 2013, pp. 99-140

aos de outros países latino americanos. O número de concluintes do Ensino Superior passou de 254.401 em 1995 para 717.858 em 2005; estes dados são reveladores, pois em 1999 já houvera um ingresso de 787.638 alunos - valor superior aos concluintes de 2005. Outros dados: os ingressantes do ano 2000 foram 897.557 e a partir desse ano superaram a casa de um milhão ao ano. Esses dados parecem apontar na existência de ao menos algum grau de dificuldade para se obter uma Graduação no país (COSTA, 2010).

O ProUni ofertou 639.802 bolsas de 2005 a 2008, sendo 58,51\% integrais e $41,49 \%$ parciais. Segundo o INEP, as IES comunitárias (confessionais ou não) tiveram 366.103 ingressos em 2007 enquanto que as IES particulares somaram 817.367 de ingressantes e as IES públicas tiveram como ingressantes, respectivamente: 298.491 (federais); 151.640 (estaduais) e 109.720 (municipais) (MAIA, 2009).

A evasão dos alunos com bolsa do ProUni é inferior ao observado nas IES privadas, segundo censo da educação superior de 2010, elaborado pelo Inep. Tendo por referência os anos de 2009 e 2010, houve 15,6\% de evasão em IES privadas. No mesmo período, entre os alunos contemplados com bolsas do programa do governo federal, esse percentual foi de apenas 4\%. O ProUni já concedera bolsas a 893.102 estudantes em todo o país, sendo que 175.215 já se formaram (EVASÃO É..., 2011). 
Artigo original

Hegemonia - Revista Eletrônica de Relações Internacionais do Centro Universitário Unieuro

ISSN: $1809-1261$

UNIEURO, Brasília, número 11, 2013, pp. 99-140

Para o primeiro semestre de 2012, o Pró-Uni ofereceu 195.030 bolsas, sendo 98.728 integrais e 96.302 parciais (50\% da mensalidade). Podiam se candidatar às bolsas integrais estudantes com renda familiar de até um salário mínimo e meio; já as bolsas parciais visavam estudantes de renda familiar de até três salários mínimos. Uma condição: ter feito o Enem 2011, com um mínimo de 400 pontos na média das cinco notas do exame e pelo menos nota mínima na redação. As vagas serão oferecidas por 28 universidades e 39 centros universitários. Fazem parte instituições paulistas como a PUC (Pontifícia Universidade Católica), Universidade Metodista, Universidade Nove de Julho, dentre outras. As inscrições para o ProUni, encerradas em janeiro de 2012 somaram 1.208.398 candidatos. O número de candidatos, o maior da história do programa supera os 1.048 .631 do processo de 2011, até então a maior marca (COMEÇAM..., 2012; MACHADO, 2012; PROUNI FECHA..., 2012).

Vitor Lima Lobo, 20 anos, foi o milionésimo estudante a conquistar uma bolsa do ProUni, ao início de 2012, ingressando na Católica de Brasília. Além da bolsa integral do ProUni, ganhou bolsa permanência de $\mathrm{R} \$$ 360,00 mensais para custeio

- como todo bolsista integral do ProUni de curso presencial com, no mínimo, seis semestres e carga horária média ou superior a seis horas por dia. Em 2010 e 2011, Vitor prestara vestibulares na Universidade Federal de Goiás e não passou. Em 2011 fez vestibular para direito na UnB e passou, mas continuou estudando para medicina. No final de 
Artigo original

Hegemonia - Revista Eletrônica de Relações Internacionais do Centro Universitário Unieuro

ISSN: $1809-1261$

UNIEURO, Brasília, número 11, 2013, pp. 99-140

2011, Vitor decidiu tentar pela última vez uma vaga em medicina e em engenharia, com a nota do Enem (LORENZONI, 2012).

Uma das instâncias educativas que promove a abertura à concepção de ser humano participativo e cidadão é o ensino superior que, não só forma profissionalmente, mar permite - mediante o tripé ensinopesquisa-extensão - transformar o projeto de participação social, fazendo-o mais democrático. Essa desenvoltura teórica encontra ressonância no ProUni, ao tentar promover um dos preceitos éticos da justiça social: o direito ao ensino superior (SILVA et al., 2010).

Críticas ao ProUni

Carvalho (2006) vê o ProUni como uma estatização de vagas nas IES particulares em troca da renúncia fiscal. Essa talvez seja a crítica mais contundente, em especial se forem analisadas inúmeras IES privadas apenas focadas no ensino, que contratam Mestres e Doutores nos períodos de avaliação e que depois os demitem, e outras práticas do estilo. Ora, a crítica se refere ao fato de o Governo "adquirir vagas no atacado" nessas IES - sendo que inúmeros autores propugnam o aumento do número de vagas nas IES públicas, nas quais a qualidade seria melhor controlada, ao lado da existência equilibrada de ensino, pesquisa e extensão. Maia (2009) aponta ainda que o ProUni foi concebido sem consultas à população e sem a certeza de sua continuidade após um prazo de dez anos. Ou seja, se constitui em uma prática de governo ao invés de uma política pública. 
Artigo original

Hegemonia - Revista Eletrônica de Relações Internacionais do Centro Universitário Unieuro

ISSN: $1809-1261$

UNIEURO, Brasília, número 11, 2013, pp. 99-140

Segenreich (2009) faz um alerta: dado que o Estado também patrocina cursos de EAD mediante o ProUni, cresce sua responsabilidade de dar conta de problemas em relação à oferta de múltiplas bases territoriais em diversos pólos que ainda não foram avaliados; às implicações decorrentes do distanciamento das IES sede em relação aos pólos, em termos de sensibilidade às diferenças regionais; e, à democratização de acesso, de permanência e de qualidade de ensino.

Há uma crítica sobre a efetividade do ProUni, pois as camadas de baixa renda não necessitam apenas de gratuidade integral ou parcial para estudar, mas de condições que apenas as instituições públicas oferecem: transporte, moradia, alimentação, assistência médica nos hospitais universitários, bolsas de trabalho e de pesquisa. Assim, o MEC passou a conceder, a partir de 2006, bolsa de permanência de $\mathrm{R} \$$ 300,00 para cobrir ao menos em parte essas despesas aos beneficiários que estudam em tempo integral, mediante a Lei $11.180 / 2005$. A iniciativa é importante, mas insuficiente, quer em termos monetários, quer por ser oferecida a apenas 4.500 alunos - valor irrisório frente aos 112 mil bolsistas de 2005. Outra crítica: nas bolsas de estudos parciais de $50 \%$, caso os beneficiários não paguem a parte que thes cabe, não é permitida a matrícula no semestre ou no ano seguinte, o que pode aumentar evasão: assim, dos 112 mil bolsistas acima citados, 95 mil permaneceram (CARVALHO, 2006; COSTA, 2010). Cabe destacar que essa bolsa de permanência foi elevada de $R \$ 300$ a $R \$ 360$ ao mês, conforme acima se relata ao milionésimo bolsista do programa. 
Artigo original

Hegemonia - Revista Eletrônica de Relações Internacionais do Centro Universitário Unieuro

ISSN: $1809-1261$

UNIEURO, Brasília, número 11, 2013, pp. 99-140

Outra crítica se refere à implantação do ProUni: pelas regras originais, as IES participantes teriam que comprovar, até 31 de dezembro do ano anterior ao de sua adesão, a sua adimplência para com os tributos federais. Mas, mediante a Medida Provisória 340, de 29/12/2006, o prazo foi adiado para 31/12/2007. Este prazo foi novamente adiado para 2008. O MEC, até maio de 2007, jamais havia informado qual era o total da dívida das IES privadas participantes do Programa nem quantas IES estariam inadimplentes. Em audiência pública de 30/05/2007 junto à Comissão de Educação e Cultura da Câmara dos Deputados, o representante da Procuradoria Geral da Fazenda Nacional (PGFN), que cuida de valores já inscritos em dívida ativa, prontos para execução judicial, explicou que os débitos das IES privadas são relativos a "fatos geradores ocorridos até final de 2006, os quais podem ser parcelados". O secretário-adjunto da Receita Federal do Brasil informou que a dívida total das IES era de quase $R \$ 12$ bilhões, sendo $70 \%$ ( $\$$ \$ 8,3 bilhões) com o INSS. Quase 11 bilhões estavam em cobrança administrativa e o restante em cobrança judicial. Outra forte crítica: o ProUni é uma opção política do MEC, não pelo apoio do sistema público federal de educação superior, mas ao sistema privado, por meio do deslocamento de recursos públicos para aquisição de vagas nas IES privadas de ensino superior (ANDRÉS RIBEIRO, 2011).

No tocante ao tema de comprovação, um aluno entrevistado da PUC-SP - da primeira geração a receber o benefício - disse ter dificuldade de comprovar renda, por ser autônomo, porém, sem implicar 
Artigo original

Hegemonia - Revista Eletrônica de Relações Internacionais do Centro Universitário Unieuro

ISSN: $1809-1261$

UNIEURO, Brasília, número 11, 2013, pp. 99-140

impossibilidade de pagar a IES; assim, ele reconhece que talvez alguém com menores condições financeiras devesse ter sido contemplado em seu lugar pelo critério de justiça. Os gastos para checar a autodeclaração da realidade socioeconômica do candidato - como, por exemplo, uma visita domiciliar - podem ser proibitivos. Em relação a essas críticas válidas, cabe o questionamento de qualquer programa social de amplo alcance: os custos de averiguação de todas as informações podem tornar inviável a implementação do programa; assim, parece razoável o exigir o fornecimento de um mínimo volume de informações que forneça bases para a tomada de decisão em relação à concessão ou não do benefício (MAIA, 2009; COSTA, 2010).

Considerando a eficiência, o ProUni preenche vagas que se encontram ociosas nas IES particulares. Além disso, as IES não lucrativas apresentam metas de Bolsas a ofertar, o que torna de maior utilidade social as isenções que essas IES recebem. Essas duas particularidades podem ser positivas. Porém, para certos grupos sociais, o ProUni ainda não representa uma solução que consiga superar suas dificuldades de inserção no Ensino Superior (MCCOWAN, 2007).

Outra crítica está ligada à ausência de transparência: o MEC não mostra o total de bolsas contratadas por IES; o tipo das IES participantes; não detalha os cursos elegíveis; os perfis econômicos e sociais dos alunos; as taxas de evasão; e nem o desempenho escolar dos beneficiários (CATANI \& HEY \& GILIOLI, 2006). 
Artigo original

Hegemonia - Revista Eletrônica de Relações Internacionais do Centro Universitário Unieuro

ISSN: $1809-1261$

UNIEURO, Brasília, número 11, 2013, pp. 99-140

Outra crítica tocante à implementação se refere à falta de controle do programa: muitos bolsistas perderam o ano, pois suas turmas foram fechadas pelas IES. Embora tenham a obrigação de destinar esses alunos a outras IES, a fiscalização não atuou. Houve bolsistas se reinscrevendo novamente no ProUni após não serem realocados em outras IES (CATANI \& HEY \& GILIOLI, 2006).

O governo publicou em abril/2012 um decreto no "Diário Oficial da União" condicionando o recebimento do seguro-desemprego à matrícula em um curso de qualificação profissional nos casos em que o benefício é solicitado pela terceira vez em um prazo de 10 anos. $O$ texto dizia que $o$ curso de qualificação precisa ser regulamentado pelo Ministério da Educação, ter carga horária mínima de 160 horas e ser concedido mediante a Bolsa-Formação Trabalhador, no âmbito do Pronatec (Programa Nacional de Acesso ao Ensino Tecnológico e Emprego). Se não houver um curso de formação profissional compatível com o perfil do trabalhador no município ou região metropolitana onde vive, o seguro-desemprego não será suspenso. O valor do benefício varia de $\mathrm{R} \$$ 622 (salário mínimo da época) a $\mathrm{R} \$ 1.163,76$, de acordo com a média salarial dos últimos salários anteriores à demissão (PRADO, 2012).

\section{Conclusões}

Enfim, talvez se possa dizer que o Estado tenha adotado na gestão da educação pública um ethos ao estilo de um neodarwinismo social, admitindo a lógica do mercado, trazendo ao domínio público inúmeros 
Artigo original

Hegemonia - Revista Eletrônica de Relações Internacionais do Centro Universitário Unieuro

ISSN: $1809-1261$

UNIEURO, Brasília, número 11, 2013, pp. 99-140

modelos de gestão privada, cuja ênfase esteja nos resultados (SOUZA; OLIVEIRA, 2003). Como contraponto, para Silva et al. (2010), o ProUni permite o desenvolvimento humano e social mediante o ingresso no ensino superior de pessoas que não teriam outras opções - muitas delas, inclusive, são adultas, e, assim, possuem expectativas bem diversas de um Curso Superior daquelas detidas por recem egressos das melhores escolas do Ensino Médio - elegíveis, pelo sistema tradicional dos vestibulares, para ingressarem nas IES Públicas, como Sotero (2009) corrobora.

Inúmeras críticas razoáveis cabem ao programa, acima resumidas cabendo algumas medidas visando evitar distorções ou paternalismos. Por exemplo, talvez alguma medida semelhante ao Projeto de Lei de condicionamento do seguro desemprego poderia ser implantado no ProUni, de modo a que a motivação dos alunos ao estudo fosse maior. Enfim, as pessoas são diferentes, tiveram oportunidades diferentes, e para inúmeras delas o ProUni pode representar uma oportunidade única de obter um Curso de nível Superior, hoje mais necessário do que nunca. Além disso, é ainda mais importante iniciar a prática habitual do aprendizado contínuo - seja pela leitura, seja pela participação em posteriores cursos, seja pela pesquisa habitual junto à internet. É ilustrador o episódio apontado - embora não possa ser generalizado referente ao milionésimo candidato: preferiu abrir mão de uma vaga em uma conceituada IES Pública na área do direito para fazer mais um ano de cursinho e buscar o tão sonhado Curso de Medicina - a ser realizado apenas mediante o ProUni, pois, tradicionalmente esse Curso é focado 
Artigo original

Hegemonia - Revista Eletrônica de Relações Internacionais do Centro Universitário Unieuro

ISSN: $1809-1261$

UNIEURO, Brasília, número 11, 2013, pp. 99-140

nas elites em nosso país. Destaca-se que o Curso de Direito do qual abriu mão afirma em seu site oferecer apenas 60 vagas por semestre de manhã e outras tantas à noite.

As sugestões do Banco Mundial apontadas por Otranto (2006) no sentido de busca de autofinanciamento pelas IES públicas dificilmente encontrariam respaldo no país, em função de toda nossa tradição no sentido de que o ensino público seja gratuito - ainda que frequentado por alunos das elevadas classes sociais. Dessa forma, as ações afirmativas se constituem ferramentas únicas para propiciar às classes menos favorecidas uma participação no ensino superior.

Os resultados parciais resumidos acima mostram um razoável grau de sucesso do programa: menores taxas de evasão, maiores notas e aumento da renda familiar dos egressos. Ora, são resultados que apontam um certo desenvolvimento social e até mesmo econômico dos participantes do programa. A aludida "compra de vagas nas IES privadas no atacado" pode ser vista como uma solução de compromisso do Governo - inevitável em qualquer sistema democrático, no qual se verificam inúmeros jogos de poder, tentativas de equilíbrios de forças, e resistências empedernidas que podem terminar por obter justamente os resultados contrários aos pretendidos. Ao mesmo tempo, não se pode negar que nas IES públicas houve substancial crescimento no número de vagas, professores, criação de novos cursos. Ou seja, o ProUni não pode ser culpado de ter "roubado" recursos do sistema público de ensino, mas deve ser realmente tido por um programa de ação 
Artigo original

Hegemonia - Revista Eletrônica de Relações Internacionais do Centro Universitário Unieuro

ISSN: $1809-1261$

UNIEURO, Brasília, número 11, 2013, pp. 99-140

afirmativa, importante no crescimento de um importante número de estudantes oriundos das classes sociais inferiores.

Em todos os países existem cursos de nível superior de maior qualidade - em parte por serem frequentados por alunos que tiveram melhores oportunidades no Ensino Básico e Médio. Porém, como Farrell (2011) apontou acima, nem Bill Gates, nem e nem Steve Jobs, e mais recentemente, nem Marck Zuckerberg concluíram cursos superiores; no entanto, criaram companhias que revolucionaram a atual sociedade por produtos e serviços lançados, criaram riqueza, geraram empregos de elevado nível a milhares de pessoas. Cabe destacar que todos os tres tiveram condições de educação ótimas ensino médio. No caso de Steve Jobs, talvez não tenha tido oportunidades típicas consideradas como as dos melhores cursos no Ensino Médio; porém segundo Minadeo e Cardoso (2004), fazia parte de um grupo, junto com Stephen Wozniak um gênio da eletrônica, que já na sexta série construiu um equipamento de rádio amador e, criou um sistema de intercomunicação casa-a-casa, instalando alto falantes nas casas dos vizinhos; na mesma época, criou um jogo da velha eletrônico. Jobs, por sua vez, tinha um enorme talento para vislumbrar oportunidades de negócio e as suas habilidades com a eletrônica também não eram desprezíveis - especialmente naqueles tempos pioneiros; e o que se viu ao longo de sua carreira foi também uma habilidade superior em design - não necessariamente proveniente de cursos formais. Novamente, essas situações corroboram as afirmações de Farrell (2011) no sentido de que alguns cursos superiores 
Artigo original

Hegemonia - Revista Eletrônica de Relações Internacionais do Centro Universitário Unieuro

ISSN: $1809-1261$

UNIEURO, Brasília, número 11, 2013, pp. 99-140

se tornaram anacrônicos em função da evolução tecnológica e cultural em curso.

Em nosso país, toda uma geração - como Samuel Klein, criador da Casas Bahia - não estudou, e nem por isso seus esforços podem ser desprezados. Em outras palavras, não se espera que o ProUni venha a criar figuras como as acima mencionadas - até porque os tempos são outros. Porém, não se pode dizer que todo seu empenho é vão apenas porque seus participantes possuem diplomas de Ensino Médio menos qualificados do que os detidos pela elite, que podem ingressar nas Universidades de maior prestígio mediante suas maiores notas de vestibular. O milionésimo bolsista ilustra isso: poderia ser um aluno de direito de uma prestigiosa IES pública, mas preferiu estudar um ano a mais, e com essa nota do Enem ingressou em um curso de Medicina em uma IES privada.

\section{REFERÊNCIAS}

A USP MUDA a pós-graduação. O Estado de São Paulo, P. A3, 10 abr. 2012.

ALMEIDA, Sergio Campos de. O avanço na privatização da educação brasileira: o ProUni como uma nova estratégia para a transferência de recursos públicos para o setor privado. Dissertação de Mestrado (Educação Brasileira). Niterói: UFF, 2006.

ANDRÉS RIBEIRO, Maria Aparecida. O PROGRAMA UNIVERSIDADE PARA TODOS (PROUNI). Câmara dos Deputados, 2011. Disponível em: 
Artigo original

Hegemonia - Revista Eletrônica de Relações Internacionais do Centro Universitário Unieuro

ISSN: $1809-1261$

UNIEURO, Brasília, número 11, 2013, pp. 99-140

<http://bd.camara.gov.br/bd/bitstream/handle/bdcamara/6264/andres_ programa_universidade.pdf?sequence=1>. Acesso em 31 jan. 2012.

ANHAIA, Bruna Cruz de. O programa universidade para todos: análise da política, do impacto e das vivências dos bolsistas. Monografia de Conclusão de Curso (Bacharel em Ciências Sociais). Porto Alegre: UFRGS. 2010.

ANHAIA, Bruna Cruz de; NEVES, Clarissa Eckert Baeta. Políticas públicas e sociais no Ensino Superior: inserção com inclusão? O Programa Universidade para Todos. Porto Alegre: X Salão de Iniciação Científica - PUCRS, 2009.

APRILE, Maria Rita; BARONE, Rosa ELISA Mirra. Políticas Públicas para Acesso ao Ensino Superior e Inclusão no Mundo do Trabalho - o Programa Universidade para todos (PROUNI) em Questão. VI Congresso Português de Sociologia. Universidade Nova de Lisboa. Mundos Sociais, Saberes e Práticas, 2006.

ARELARO, Lisete R. G. Formulação e implementação das políticas públicas em educação e as parcerias público-privadas: impasse democrático ou mistificação política? Campinas: Educ. Soc., vol. 28, n. 100 - Especial, p. 899-919, out. 2007.

Disponível em <http://www.cedes.unicamp.br>.

BEATTY, Jack. O mundo segundo Peter Drucker. São Paulo: Editora Futura. 1998, p. 165).

BORLINA FILHO, Venceslau. Aumenta o número de brasileiros com ensino superior completo. Folha Online, 27 abr. 2012. 
Artigo original

Hegemonia - Revista Eletrônica de Relações Internacionais do Centro Universitário Unieuro

ISSN: $1809-1261$

UNIEURO, Brasília, número 11, 2013, pp. 99-140

CARVALHO, Cristina Helena Almeida de. Política de ensino superior e renúncia fiscal: da Reforma Universitária de 1968 ao ProUni. ANPED, 2005.

CARVALHO, Cristina Helena Almeida de. O PROUNI no Governo Lula e o jogo político em torno do acesso ao ensino superior. Educ. Soc., Campinas, vol. 27, n. 96 - Especial, p. 979-1000, out. 2006.

CATANI, Afrânio Mendes; HEY, Ana Paula Hey; GILIOLI, Renato de Sousa Porto. PROUNI: democratização do acesso às Instituições de Ensino Superior? Curitiba: Editora UFPR, Educar, n. 28, p. 125-140, 2006.

CERIBELI, Harrison Bachion; PRADO, Lucas Sciencia do; MERLO, Edgard Monfort. Uma aplicação conjunta das análises SWOT/PEST para avaliação de estratégias competitivas no varejo. Revista Ibero Americana de Estratégia - RIAE, v. 9, n. 1, p. 77-101, jan./abr; 2010.

COSTA, Fabiana. ProUni - O olhar dos estudantes beneficiários. Curitiba: Editora Michelotto, 2010.

DE REZENDE VERGARA, Moema. Contexto e Conceitos: História da Ciência e "Vulgarização Científica" no Brasil do Século XIX. Interciencia; May 2008; 33， 5; PRISMA (Publicaciones y Revistas Sociales y Humanísticas), p. 324-330.

ENSINO MÉDIO deveria ter, pelo menos, mais 2 milhões de alunos. Portal iG, 18 abr. 2012.

EVASÃO é inferior à média do sistema universitário nacional. Portal do MEC, 22 ago. 2011. Disponível em: 
Artigo original

Hegemonia - Revista Eletrônica de Relações Internacionais do Centro Universitário Unieuro

ISSN: $1809-1261$

UNIEURO, Brasília, número 11, 2013, pp. 99-140

<http://portal.mec.gov.br/index.php?option=com_content\&view=article \&id=16993: evasao-e-inferior-a-media-do-sistema-universitarionacional\&catid=212\&Itemid=86> . Acesso em 01 fev. 2012.

FARRELL, Chris. A College Degree Is Still Worth It. Business Week Online, 20 mar. 2011.

FEGHALI, Jandira; BAHIA, Lígia. O papel do Estado no financiamento da saúde. Princípios, n. 114, set. 2011, p. 16-22.

FLETCHER, Michael A. Unemployment drop still leaves low skill workers behind. Washington Times Online, 07 fev. 2012.

GALLUCCI, Mariângela. ProUni pode adotar políticas afirmativas, decide Supremo. O Estado de São Paulo, P. A22, 04 mai. 2012.

HANDY, C. A Era da Irracionalidade - ou a Gestão do Futuro. Portugal: Edições Cetop, 1992.

HUNTER, Wendy; SUGIYAMA, Natasha Borges. Democracy and Social Policy in Brazil: Advancing Basic Needs, Preserving Privileged Interests. Latin American Politics and Society; Summer 2009; 51, 2; pg. 29-58. KALENA, Fernanda. Área de humanas se propaga pelo interior. Folha Online, 18 fev. 2012.

LORENZONI, Ionice. Bolsista número 1 milhão quer uma medicina mais humana. Portal do MEC, 23 jan. 2012. Disponível em:

<http://portal.mec.gov.br/index.php?option=com_content\&view=article \&id=17412> . Acesso em: 01 fev. 2012.

MACHADO, Renato. MEC divulga relação de instituições que oferecerão ProUni. Folha Online, 04 jan. 2012.

MAIA, Suzanir Fernanda. O Programa Universidade para Todos (ProUni) nas IES Comunitárias: a experiência da Universidade Católica de Goiás 
Artigo original

Hegemonia - Revista Eletrônica de Relações Internacionais do Centro Universitário Unieuro

ISSN: $1809-1261$

UNIEURO, Brasília, número 11, 2013, pp. 99-140

(2005-8). Dissertação (Mestrado em Educação). Mato Grosso do Sul, Campo Grande: Universidade Dom Bosco, 2009.

MAIS DE 140 mil já contrataram o FIES este ano, afirma Dilma. Folha Online, 09 abr. 2012.

MANDELLI, Mariana. Em uma década, cursos tecnológicos receberam $547 \%$ mais alunos em SP. O Estado de São Paulo, p. A10, 21 fev. 2012.

MCCOWAN, Tristan. Expansion without equity: An analysis of current policy on access to higher education in Brazil. Higher Education (2007) 53: 579-598.

MINADEO, Roberto; CARDOSO, Ricardo Muniz. "Apple: Ruim com Steve Jobs - Mas Impossível sem ele." II Encontro de Pós-Graduação em História Econômica. Niterói: UFF. 05-07 set. 2004.

MOURA, Dante Henrique (Coord. Editorial). Educação profissional técnica de nível médio integrada ao ensino médio. Secretaria de Educação Profissional e Tecnológica. Portal do Mec, dez. 2007. Disponível em: $<$ http://portal.mec.gov.br/setec/arquivos/pdf/documento_base.pdf>. Acesso em 22 fev. 2012.

PAÍS tem 3,8 mi fora da escola e não atinge meta, diz estudo. Folha Online, 07 fev. 2012.

OTRANTO, Celia Regina. A reforma da educação superior do Governo Lula: da inspiração à implantação. ANPED, 2006.

PARAGUASSÚ, L. ProUni faz taxa de alunos com emprego subir de 56\% para 80\%. O Estado de São Paulo Online, 21 abr. 2009.

PEREIRA, Thiago Ingrassia; SILVA, Luís Fernando Santos Corrêa da. As políticas públicas do ensino superior no governo Lula: expansão ou 
Artigo original

Hegemonia - Revista Eletrônica de Relações Internacionais do Centro Universitário Unieuro

ISSN: $1809-1261$

UNIEURO, Brasília, número 11, 2013, pp. 99-140

democratização? Porto Alegre: Revista Debates, v. 4, n. 2, p. 10-31, jul.-dez. 2010.

PRADO, Maeli. Trabalhador terá de fazer curso para ganhar segurodesemprego. Folha Online, 17 abr. 2012.

PROUNI FECHA fecha inscrições com recorde de 1,2 milhão de candidatos. Folha Online, 20 jan. 2012.

SANTOS, Frei David OFM. Ações afirmativas e o judiciário. Revista da Escola Nacional da Magistratura, v. 11, n. 3, abr/2007, p. 113-128.

SEGENREICH, Stella Cecília Duarte. ProUni e UAB como estratégias de EAD na expansão do Ensino Superior. Pro-Posições, Campinas, v. 20, n. 2 (59), p. 205-222, maio/ago. 2009.

SELIGMAN, Felipe. Julgamento do STF confirma legalidade do ProUni. Folha Online, 03 mai. 2012.

SILVA, Lauraci Dondé da; MENDES Tania Maria Scuro Mendes; OLIVEIRA, Maria Cleidia Klein; LEMKE, Fernanda Lemke; GOULART, Bianca Daniete Chimello Goulart. Aluno do ProUni: acesso democrático ao ensino superior. O que garante a sua permanência? Brasília, Conselho de Reitores das Universidades Brasileiras - CRUB, Educação Brasileira, Brasília, v. 32, n. 64, janeiro a junho de 2010, p. 58-78.

SOTERO, Edilza Correia. Negros no ensino superior - Trajetória e Expectativa de Estudantes de Administração beneficiados por Políticas de Ação Afirmativa (ProUni e Cotas) em Salvador. Dissertação de Mestrado (Sociologia). São Paulo: USP, 2009.

SOUZA, Sandra Zákia Lian de Souza; OLIVEIRA, Romualdo Portela de. Políticas de avaliação da educação e quase mercado no Brasil. 
Artigo original

Hegemonia - Revista Eletrônica de Relações Internacionais do Centro

Universitário Unieuro

ISSN: $1809-1261$

UNIEURO, Brasília, número 11, 2013, pp. 99-140

Campinas: Educ. Soc., vol. 24, n. 84, p. 873-895, setembro 2003.

Disponível em:

$<$ http://www.cedes.unicamp.br>.

TEOTÔNIO, Paulo José Freire; SILVA, Flávia Regina Ribeiro da. O

Programa Universidade para todos (ProUni): Alternativa para uma Sociedade inclusiva? Direitos Humanos, Sociedade e Reforma do

Estado, Coord. Paulo José Freire Teotônio e outra. Campinas, São Paulo: Millennium Editora, 2006, p. 49-98. 